\title{
Anxiety, Depression and their Risk Factors in Cancer Moroccan Patients Undergoing Radiation Therapy: A Cross-Sectional Study
}

\author{
ElKacemi $\mathrm{H}^{*}$, Aarab J, ElMajjaousi S, Kebdani T and Benjaafar $\mathbf{N}$
}

Faculty of Medicine and Pharmacy, Mohammed V University of Rabat, Rabat, Morocco

\begin{abstract}
Purpose: To our knowledge, no study specifically assessed anxiety and depression in Moroccan cancer population undergoing radiotherapy. The objective of this study was to assess the prevalence of anxiety and depression in patients with cancer prior to the first session of radiotherapy and to identify predictor factors.

Material and methods: It is a cross-sectional single center study. An interview was conducted using the Hospital Anxiety and Depression Scale.

Results: 150 patients filled the study inclusion criteria. The mean age was $54.9 \pm 12.8$ years, $12 \%$ of patients were in current employment. $42 \%$ of the participants had a positive family history of cancer. Out of study participants, $58 \%$ scored abnormal on the anxiety scale and $52 \%$ on the depression scale. Statistically significant predictors of anxiety and depression were similar to those reported in published studies, such as the presence of family history of cancer, received radiotherapy in family, employment status and treatment intention.

Conclusions: The results of this study suggest that a large proportion of cancer patients have psychiatric comorbidities. There is an urgent need for psychosocial support programs and psychological screening for patients diagnosed with cancer and candidate for radiation therapy.
\end{abstract}

Keywords: Anxiety; Depression; Hospital anxiety and depression scale; Radiation therapy

\section{Introduction}

Many patients experience a multitude of physical, psychological and psychosomatic symptoms after being diagnosed with cancer. This often results in a deterioration of the physical and psychosocial condition of these patients [1]. Radiation therapy is an integral part of cancer management, 30 to $50 \%$ of all patients with cancer receive irradiation, either alone or in combination with surgery and chemotherapy [2]. In the literature it is expressed that radiotherapy is a stress factor among cancer treatment methods because it has a lot misunderstood concerning it.

\section{Aim}

In this present study, we have prospectively assessed anxiety and depression scores prior at the first radiotherapy session in patients with different tumor and also to identified predictor factors.

\section{Material and Method}

\section{Subjects and setting}

Patients aged 18 years or older with different type of cancer, who were receiving extern beam radiotherapy for the first time of their life in our department, between July and September 2017, had no cognitive dysfunction, able of hearing normal conversation, oriented to time and place, speaking Arabic. Provided consent were included in the study.

\section{Study design and assessment}

This study is a cross-sectional, single center study. Eligible participants who consented to participate in our study were interviewed alone by a doctor, unless they preferred to be accompanied by a family member. Assessments happened at the first session of radiotherapy. The Hospital Anxiety and Depression Scale (HADS) was the tool used to measure anxiety and depression disorder prior to the beginning of radiotherapy.

\section{Questionnaires}

Social, demographic and clinical characteristics: Patients provided demographic information, including gender, age, marital status (married vs. not married), educational level (low education $v s$. moderate or high educational level), financial status (low level $v s$. moderate or high level), employment status (working actually or no), living environment (urban vs. rural), children in charge (yes or no), family support (yes or no), cancer in the entourage (yes or no), family history of cancer while specifying if this member had received radiotherapy, idea about radiotherapy treatment (yes or no), having pain (yes or no), taking anxiolytics (yes or no).

Disease related characteristics: Physician provided data about patients disease and treatment characteristics, including months since diagnoses ( $<3$ months or $\geq 3$ months), localization, disease stage, treatment intention (curative or palliative), received treatments (surgery and chemotherapy), the use of thermoplastic mask (yes $v s$. no) and performance status as defined by the Eastern Cooperative Oncology Group (ECOG) (0=optimum performance status, $4=$ worst performance status) [3], Patients with an ECOG score of 0 or 1 were categorized as having good performance status, and those with a score of 2 to 4 were categorized as having moderate to poor performance status.

*Corresponding author: Hanan El Kacemi, Faculty of Medicine and Pharmacy Mohammed V University of Rabat, Rabat, Morocco, Tel: 00212662436121; E-mail: elkacemihanan@yahoo.fr

Received March 12, 2018; Accepted April 06, 2018; Published April 10, 2018

Citation: ElKacemi H, Aarab J, ElMajjaousi S, Kebdani T, Benjaafar N (2018) Anxiety, Depression and their Risk Factors in Cancer Moroccan Patients Undergoing Radiation Therapy: A Cross-Sectional Study. J Nucl Med Radiat Ther 9: 361. doi: 10.4172/2155-9619.1000361

Copyright: (c) 2018 ElKacemi $\mathrm{H}$, et al. This is an open-access article distributed under the terms of the Creative Commons Attribution License, which permits unrestricted use, distribution, and reproduction in any medium, provided the original author and source are credited. 
Citation: ElKacemi H, Aarab J, EIMajjaousi S, Kebdani T, Benjaafar N (2018) Anxiety, Depression and their Risk Factors in Cancer Moroccan Patients Undergoing Radiation Therapy: A Cross-Sectional Study. J Nucl Med Radiat Ther 9: 361. doi: 10.4172/2155-9619.1000361

Page 2 of 5

Hospital Anxiety and Depression Scale (HADS): Depression and anxiety are generally considered to be the most important psychopathological comorbidities of cancer patients. The Hospital Anxiety and Depression Scale (HADS) identify symptoms of anxiety and depression in patients with somatic disorders [4]. The HADS is widely used to measure distress in patients with cancer [5]. This questionnaire was also validated on Arab populations [6]. A systematic review of a large number of studies identified a cut-off point of $8 / 21$ for anxiety or depression. For anxiety (HADS-A) this gave a specificity of 0.78 and a sensitivity of 0.9 . For depression (HADS-D) this gave a specificity of 0.79 and a sensitivity of 0.83 [7]. The HADS includes 14 items, seven for each anxiety (HAD-A) and depression (HAD-D). Each item is scored from 0 to 3 ( $0=$ no problems to $3=$ maximum distress) [4]. Patients could be categorized based on their individual sum scores: Non-case (0-7), borderline case (8-10) and definitive case (11 and above) [4]. To identify patients with at least moderate symptoms of anxiety and depression, we used a cut-off score of $\geq 8$.

\section{Statistical analysis}

Statistical analyses were performed using IBM SPSS Statistics 14. A descriptive analysis was made, with frequency distributions for qualitative variables and calculation of the mean and standard deviation (SD) for quantitative variables to categorize patients according to demographic, social and treatment characteristics. The association between different factors and HAD scores was assessed in univariate and multivariate binary logistic regressions using stepwise selection method (alpha-to-enter of 0.05 , alpha-to-remove of 0.1 ).

\section{Results}

Of the 160 patients screened for eligibility, 150 filled the study inclusion criteria and completed the interview. The mentioned reasons for not participating were feeling tired $(n=1)$, not able to answer $(n=5)$, already received radiotherapy $(n=4)$.

The mean age of the patients at the time of interview was 54.9 \pm 12.8 years. $68 \%$ of the patients were married, $12 \%$ were in current employment. Regarding the family history of the study participants, $42 \%$ of the participants had a positive family history of cancer and $42.9 \%$ of whose received radiotherapy. Table 1 shows the social, demographic and clinical related characteristics of the patients in the sample.

\begin{tabular}{|l|l|}
\hline Characteristics & N (\%) \\
\hline Sex & $111(74 \%)$ \\
\hline Female & $39(26 \%)$ \\
\hline Male & \\
\hline Age & $99(68 \%)$ \\
\hline$<60$ years & $51(34 \%)$ \\
\hline$\geq 60$ years & \\
\hline Marital status & $93(62 \%)$ \\
\hline Married & $57(38 \%)$ \\
\hline Other status & \\
\hline Educational level & $129(86 \%)$ \\
\hline Low & $21(14 \%)$ \\
\hline Moderate or high & \\
\hline Financial level & $96(64 \%)$ \\
\hline Low level & $54(36 \%)$ \\
\hline Moderate or high level & \\
\hline Living environment & $123(82 \%)$ \\
\hline Urbain & $27(18 \%)$ \\
\hline Rural & \\
\hline Employement status & \\
\hline & \\
\hline
\end{tabular}

\begin{tabular}{|l|l|}
\hline Working actually & $18(12 \%)$ \\
\hline Not working & $132(88 \%)$ \\
\hline Children in charge & $123(82 \%)$ \\
\hline Yes & $27(18 \%)$ \\
\hline No & $135(90 \%)$ \\
\hline Family support & $15(10 \%)$ \\
\hline Yes & \\
\hline No & $27(18 \%)$ \\
\hline Cancer in the entourage & $123(82 \%)$ \\
\hline Yes & \\
\hline No & $63(42 \%)$ \\
\hline Family history of cancer & $27(42.9 \%)$ \\
\hline Yes & \\
\hline Received radiotherapy in family (yes) & $30(20 \%)$ \\
\hline Idea about radiotherapy & $120(80 \%)$ \\
\hline Yes & \\
\hline No & $54(36 \%)$ \\
\hline Pain & $96(64 \%)$ \\
\hline Yes & \\
\hline No & $196(96 \%)$ \\
\hline Taking anxiolytics & $196 \%$ \\
\hline Yes & \\
\hline No & \\
\hline
\end{tabular}

Table 1: Demographic and clinical characteristics of the study population $(\mathrm{N}=150)$

\begin{tabular}{|c|c|}
\hline Characteristics & N (\%) \\
\hline \multicolumn{2}{|l|}{ Diangnosis } \\
\hline Breast cancer & $60(40 \%)$ \\
\hline Cervical cancer & $24(16 \%)$ \\
\hline Rhinopharyngeal cancer & $15(10 \%)$ \\
\hline Prostate cancer & $15(10 \%)$ \\
\hline Lung cancer & $12(8 \%)$ \\
\hline Glioblastoma & $6(4 \%)$ \\
\hline Laryngeal cancer & $6(4 \%)$ \\
\hline Vulvar cancer & $3(2 \%)$ \\
\hline Endometrial cancer & $3(2 \%)$ \\
\hline \multicolumn{2}{|l|}{ Disease Stage } \\
\hline Stage I or II & $84(58.3 \%)$ \\
\hline Stage III or IV & $60(41.7 \%)$ \\
\hline \multicolumn{2}{|l|}{ Treatment intention } \\
\hline Curative & $135(90 \%)$ \\
\hline Palliative & $15(10 \%)$ \\
\hline \multicolumn{2}{|l|}{ Months since diagnosis } \\
\hline$<3$ months & $39(26 \%)$ \\
\hline$\geq 3$ months & $111(74 \%)$ \\
\hline \multicolumn{2}{|c|}{ Treatments modality received } \\
\hline Surgery (yes) & $93(62 \%)$ \\
\hline Chemotherapy (yes) & $66(44 \%)$ \\
\hline \multicolumn{2}{|l|}{ Performance status } \\
\hline PS 0 to 1 & $141(94 \%)$ \\
\hline PS 2 to 4 & $9(6 \%)$ \\
\hline \multicolumn{2}{|l|}{ Thermoplastic mask } \\
\hline Yes & $24(36 \%)$ \\
\hline No & $114(76 \%)$ \\
\hline
\end{tabular}

Table 2: Treatment and disease related characteristics.

The analysis of disease related characteristics revealed that $90 \%$ of participants had curative treatment, while the rest had a palliative treatment (10\%). The percentage of patients who had stage I or II and II or IV was $58.3 \%$ and $41.7 \%$ respectively. Regarding treatment modalities received, $62 \%$ of participants underwent surgery and $44 \%$ underwent 
Citation: ElKacemi H, Aarab J, EIMajjaousi S, Kebdani T, Benjaafar N (2018) Anxiety, Depression and their Risk Factors in Cancer Moroccan Patients Undergoing Radiation Therapy: A Cross-Sectional Study. J Nucl Med Radiat Ther 9: 361. doi: 10.4172/2155-9619.1000361
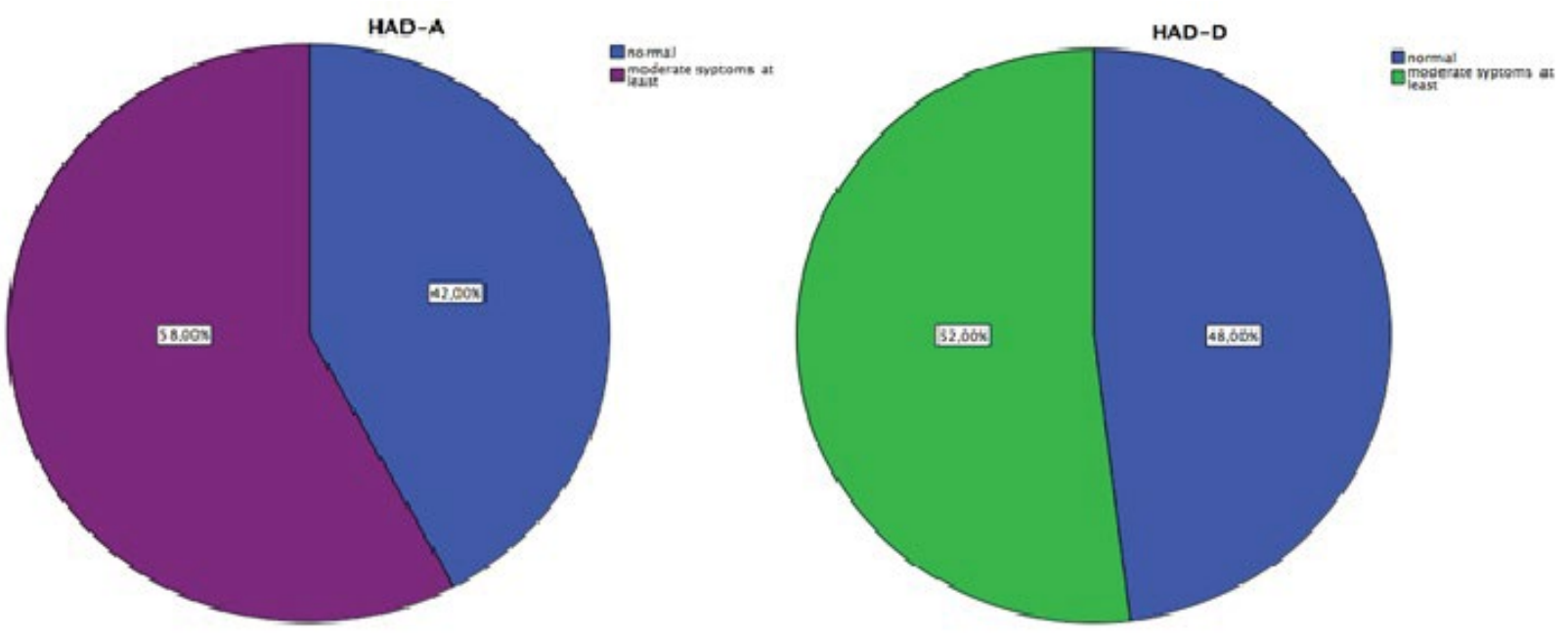

Figure 1: Percentage of patients classified as normal or having at least moderate symptoms according to HADS.

\section{Anxiety}

Normal case (HAD-A $\leq 7)$

Bordeline case $(8 \leq \mathrm{HAD}-\mathrm{A} \leq 10$

$63(42 \%)$

$45(30 \%)$

Definitive case (HAD-A $\geq 11)$ $42(28 \%)$

Depression

Normal case (HAD-D $\leq 7)$

Bordeline case $(8 \leq \mathrm{HAD}-\mathrm{D} \leq 10)$

$72(48 \%)$

$24(16 \%)$

Definitive case (HAD-D $\geq 11$ )

$54(36 \%)$

Table 3: Psychopathological comorbidity: Anxiety and depression.

\begin{tabular}{|l|l|l|l|l|l|l|}
\hline \multirow{2}{*}{ Variables } & \multicolumn{3}{|c|}{ Univariate analysis } & \multicolumn{3}{c|}{ Multivariate analysis } \\
\cline { 2 - 7 } & OR & IC & p & OR & IC & $p$ \\
\hline
\end{tabular}

Age

$<60$ years

\begin{tabular}{|l|l|l|}
0.73 & $0.37-1.4$ & 0.36
\end{tabular}

$\geq 60$ years

Sex

\begin{tabular}{|l|l|l|l|l|l|l|l|}
\hline Female & 1.25 & $0.6-2.6$ & 0.54 & - & - & - \\
\hline Male & & & & & & \\
\hline Marital status & 2.02 & $1.03-3.9$ & 0.04 & 1.49 & $0.68-3.25$ & 0.31 \\
\hline Married & & & & & & \\
\hline Other status & & & & & & \\
\hline
\end{tabular}

Educational level

\begin{tabular}{|l|l|l|l|l|l|l|l|}
\hline Low & 0.93 & $0.41-2.64$ & 0.93 & - & - & - \\
\hline Moderate or high & & & & & & \\
\hline Financial level & 0.6 & $0.3-1.1$ & 0.13 & - & - & - \\
\hline Low level & & & & & \\
\hline Moderate or high level & & & & & & \\
\hline Living environment & 0.88 & $0.3-2.05$ & 0.77 & - & - & - \\
\hline Urban & & & & & & \\
\hline Rural & & & & & \\
\hline Employement status & & & & & & \\
\hline Working actualy & 0.11 & $0.31-0.41$ & 0.001 & 0.07 & $0.01-0.36$ & 0.002 \\
\hline
\end{tabular}

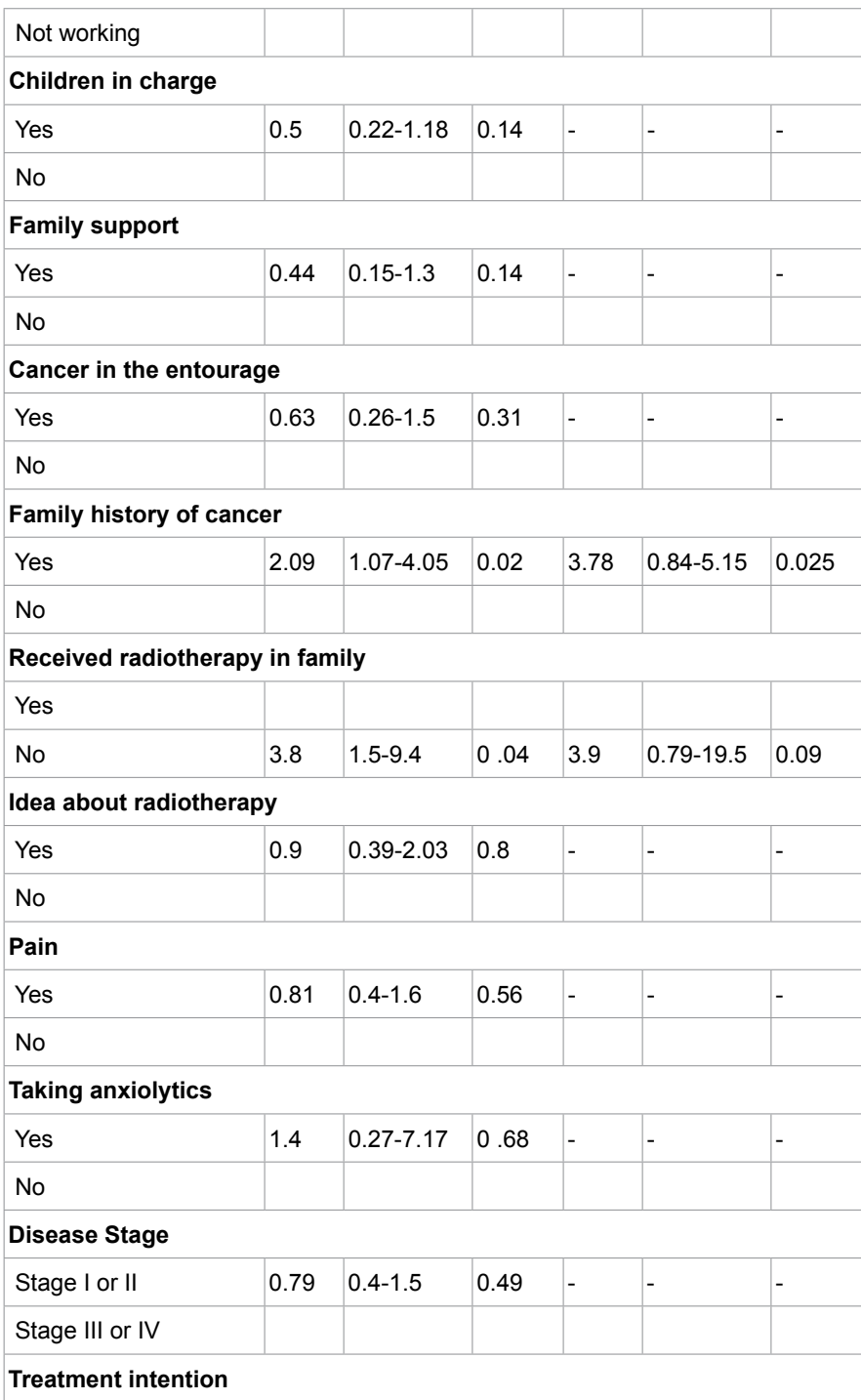


Citation: ElKacemi H, Aarab J, EIMajjaousi S, Kebdani T, Benjaafar N (2018) Anxiety, Depression and their Risk Factors in Cancer Moroccan Patients Undergoing Radiation Therapy: A Cross-Sectional Study. J Nucl Med Radiat Ther 9: 361. doi: 10.4172/2155-9619.1000361

Page 4 of 5

\begin{tabular}{|c|c|c|c|c|c|c|}
\hline Curative & 3.2 & $0.86-11.8$ & 0.08 & 5.14 & $1.02-25.8$ & 0.047 \\
\hline \multicolumn{7}{|l|}{ Palliative } \\
\hline \multicolumn{7}{|c|}{ Months since diagnosis } \\
\hline$<3$ months & 1.2 & $0.57-2.5$ & 0.6 & - & - & - \\
\hline \multicolumn{7}{|l|}{$\geq 3$ months } \\
\hline \multicolumn{7}{|c|}{ Received Surgery } \\
\hline Yes & 0.49 & $0.2-0.98$ & 0.04 & 0.86 & $0.32-2.31$ & 0.77 \\
\hline \multicolumn{7}{|l|}{ No } \\
\hline \multicolumn{7}{|c|}{ Received Chemotherapy } \\
\hline Yes & 1.8 & $0.93-3.47$ & 0.08 & & $0.84-5.15$ & 0.11 \\
\hline \multicolumn{7}{|l|}{ No } \\
\hline \multicolumn{7}{|c|}{ Performance status } \\
\hline PS 0 or 1 & - & - & 0.99 & - & - & - \\
\hline \multicolumn{7}{|l|}{ PS 2 to 4} \\
\hline \multicolumn{7}{|c|}{ Thermoplastic mask } \\
\hline Yes & 0.98 & $0.45-2.1$ & 0.96 & - & - & - \\
\hline No & & & & & & \\
\hline
\end{tabular}

Table 4: Estimated logistic regressions coefficients for the HAD-A score.

\begin{tabular}{|c|c|c|c|c|c|c|}
\hline \multirow[t]{2}{*}{ Variables } & \multicolumn{3}{|c|}{ Univaried analysis } & \multicolumn{3}{|c|}{ Multivaried analysis } \\
\hline & OR & IC & p & OR & IC & p \\
\hline \multicolumn{7}{|l|}{ Age } \\
\hline$<60$ years & 0.74 & $0.37-1.45$ & $0.38-$ & & - & - \\
\hline \multicolumn{7}{|l|}{$\geq 60$ years } \\
\hline \multicolumn{7}{|l|}{ Sex } \\
\hline Female & \multicolumn{2}{|c|}{\begin{tabular}{|l|l|}
0.9 & $0.43-1.88$
\end{tabular}} & \multicolumn{2}{|l|}{$0.78-$} & - & - \\
\hline Male & & & & & & \\
\hline \multicolumn{7}{|l|}{ Marital status } \\
\hline Married & $1.34 \mathrm{C}$ & $0.69-2.61$ & $0.37-$ & & - & - \\
\hline \multicolumn{7}{|l|}{ Other status } \\
\hline \multicolumn{7}{|l|}{ Educational level } \\
\hline Low & 1.53 & $0.6-3.89$ & $0.36-$ & - & - & - \\
\hline \multicolumn{7}{|l|}{ Moderate or high } \\
\hline \multicolumn{7}{|l|}{ Financial level } \\
\hline Low level & 0.43 & $0.22-0.86$ & 0.017 & 0.6 & $0.28-1.2$ & 0.19 \\
\hline \multicolumn{7}{|l|}{ Moderate or high level } \\
\hline \multicolumn{7}{|l|}{ Living environment } \\
\hline Urban & 1.19 & $0.51-2.75$ & $0.68-$ & & - & - \\
\hline \multicolumn{7}{|l|}{ Rural } \\
\hline \multicolumn{7}{|l|}{ Employement status } \\
\hline Working actualy & 0.15 & $0.04-0.55$ & 0.004 & 0.16 & $0.04-1.2$ & 0.008 \\
\hline \multicolumn{7}{|l|}{ Not working } \\
\hline \multicolumn{7}{|l|}{ Children in charge } \\
\hline Yes & 0.69 & $0.29-1.59$ & $0.38-$ & & - & - \\
\hline \multicolumn{7}{|l|}{ No } \\
\hline \multicolumn{7}{|l|}{ Family support } \\
\hline Yes & 0.58 & $0.19-1.73$ & $0.33-$ & & - & - \\
\hline \multicolumn{7}{|l|}{ No } \\
\hline \multicolumn{7}{|l|}{ Cancer in the entourage } \\
\hline Yes & 0.84 & $0.36-1.94$ & $0.68-$ & & - & - \\
\hline \multicolumn{7}{|l|}{ No } \\
\hline \multicolumn{7}{|l|}{ Family history of cancer } \\
\hline Yes & 1.35 & $0.7-2.59$ & $0.36-$ & & - & - \\
\hline No & & & & & & \\
\hline
\end{tabular}

\begin{tabular}{|c|c|c|c|c|c|c|}
\hline \multicolumn{7}{|c|}{ Received radiotherapy in family } \\
\hline Yes & & & & & & \\
\hline No & 4.3 & $1.5-11.7$ & 0.004 & 3.79 & $1.1-12.1$ & 0.024 \\
\hline \multicolumn{7}{|c|}{ Idea about radiotherapy } \\
\hline Yes & 1.8 & $0.81-4.13$ & 0.14 & - & - & - \\
\hline \multicolumn{7}{|l|}{ No } \\
\hline \multicolumn{7}{|l|}{ Pain } \\
\hline Yes & 1.13 & $0.58-2.2$ & 0.71 & - & - & - \\
\hline \multicolumn{7}{|l|}{ No } \\
\hline \multicolumn{7}{|c|}{ Taking anxiolytics } \\
\hline Yes & 1.08 & $0.21-5.56$ & 0.92 & - & - & - \\
\hline \multicolumn{7}{|l|}{ No } \\
\hline \multicolumn{7}{|l|}{ Disease Stage } \\
\hline Stage I or II & 0.86 & $0.44-1.68$ & 0.67 & - & - & - \\
\hline \multicolumn{7}{|l|}{ Stage III or IV } \\
\hline \multicolumn{7}{|c|}{ Treatment intentien } \\
\hline Curative & 1.4 & $0.48-4.25$ & 0.51 & - & - & - \\
\hline \multicolumn{7}{|l|}{ Palliative } \\
\hline \multicolumn{7}{|c|}{ Months since diagnosis } \\
\hline$<3$ months & 1.1 & $0.58-2.2$ & 0.78 & - & - & - \\
\hline \multicolumn{7}{|l|}{$\geq$ 3months } \\
\hline \multicolumn{7}{|c|}{ Received surgery } \\
\hline Yes & 0.68 & $0.35-1.32$ & 0.25 & - & - & - \\
\hline \multicolumn{7}{|l|}{ No } \\
\hline \multicolumn{7}{|c|}{ Received chemotherapy } \\
\hline Yes & 1.6 & $0.83-3.06$ & 0.15 & - & - & - \\
\hline \multicolumn{7}{|l|}{ No } \\
\hline \multicolumn{7}{|c|}{ Performance status } \\
\hline PS 0 or 1 & - & - & 0.99 & - & - & - \\
\hline \multicolumn{7}{|l|}{ PS 2 to 4} \\
\hline \multicolumn{7}{|c|}{ Thermoplastic mask } \\
\hline Yes & 1.1 & $0.52-2.3$ & 0.78 & - & - & - \\
\hline No & & & & & & \\
\hline
\end{tabular}

Table 5: Estimated logistic regressions coefficients for the HAD-D score.

chemotherapy. Table 2 shows the disease related characteristics of the patients in the sample.

The results derived from the HADS show that $58 \%$ of the study participants suffered from at least moderate symptoms of anxiety, and $52 \%$ from at least moderate symptoms of depression. (Figure 1 and Table 3 ). The statistically significant predictors of anxiety score were a family history of cancer, employment status, and treatment intention. For depression score, only employment status and received radiotherapy in the family were a significant predictor factors. Results of the stepwise method are shown in Table 4 for the HAD-A score and Table 5 for the HAD-D score.

\section{Discussion}

Anxiety and depression are a common disorder in cancer patients. In a systematic review and meta-analysis in cancer Chinese population that evaluated 17 studies, the reported prevalence of anxiety and depression was $49.69 \%$ and $54.90 \%$ respectively [8]. Another review conducted in Germany using the HADS has noted $28.6 \%$ of anxiety and $25.5 \%$ of depression problems in cancer patients [9]. The prevalence of anxiety and depression disorder in our sample is higher. A possible explanation for why our rates are higher than those in other studies is that the majority of our patients have a low financial status, worrying about treatment cost and family financial difficulties. On the other hand, development country like Germany, have lower prevalence of mental health problems as compared to developing countries like morocco 
[10], patients with cancer can have easily a screening for detecting psychopathological comorbidity and providing psychotherapeutic support.

Focusing on Arab populations, In Jordany, depression was found in $45 \%$ and anxiety disorder was found in $58 \%$ of female breast cancer patients [11]. Another study conducted also on female breast cancer patients in Levant, noted that $41.3 \%$ of participants scoring abnormal on the anxiety subscale and $24.7 \%$ on the depression subscale [12]. This difference can be explained that our study regroups different type of cancer. This might reflect differences in treatments or prognosis. Some cancer types are associated with worse side effects from radiotherapy treatment [13].

Family history of cancer and received radiotherapy in family were an important predictor factor of anxiety score and depression score respectively. Our results are the same from those reported in Jordan study [11]. Because of knowing more information about cancer, people have less severe fear of these treatments [14]. It is recommended that counselors and psychosocial support programs should also focus on the family history.

This study has several strengths including the use of standardized measures for the assessment of anxiety and depression, a relatively large sample size and one of the few available studies that evaluates specific psychiatric disorders in Africa and Arab cancer population.

Among the major limitations of this study was to not compare anxiety and depression scores of the same individuals at several time of radiotherapy treatment. Being a cross-sectional study might introduce some selection bias, we made an effort to include as many patients being seen in our department as possible during the recruitment period.

\section{Conclusion}

The results of this study suggest that a large proportion of cancer patients have psychiatric comorbidities and disorder. There is an urgent and vital need for psychosocial support programs and psychological screening for patients diagnosed with cancer candidate for radiation therapy.

\section{Reference}

1. Waller A, Williams A, Groff SL, Bultz BD, Carlson LE (2011) Screening for distress, the sixth vital sign: Examining self-referral in people with cancer over a one-year period. Psycho-Oncol 2: 388-395.

2. Porter A, Aref A, Chodounsky Z, Elzawawy A, Manatrakul N, et al. (1999) A global strategy for radiotherapy: A WHO consultation. Clin Oncol 11: 368-370.

3. Oken MM, Creech RH, Tormey DC, Horton J, Davis TE, et al. (1982) Toxicity and response criteria of the eastern cooperative oncology group. Am J Clin Oncol 5: 649-656.

4. Zigmond AS, Snaith RP (1983) The hospital anxiety and depression scale. Acta Psychiatr Scand 67: 361-370.

5. Singer S, Kuhnt S, Götze H, Hauss J, Hinz A, et al. (2009) Hospital anxiety and depression scale cutoff scores for cancer patients in acute care. $\mathrm{Br} \mathrm{J}$ Cancer 100: 908-912.

6. El-Rufaie OEFA, Absood G (1897) Validity study of the hospital anxiety and depression scale among a group of Saudi patients. Br J Psychiatry 151: 687-688.

7. Bjelland I, Dahl AA, Haug TT, Neckelmann D (2002) The validity of the hospital anxiety and depression scale. An updated literature review. J Psychosom Res 52: $69-77$

8. Yang YL, Liu L, Wang Y, Wu H, Yang XS, et al. (2013) The prevalence of depression and anxiety among chinese adults with cancer: $A$ systematic review and meta-analysis BMC Cancer 13.

9. Frick E, Tyroller M, Panzer M (2007) Anxiety, depression and quality of life of cancer patients undergoing radiation therapy: A cross-sectional study in a community hospital outpatient centre. Eur J Cancer Care 16: 130-136.

10. Demyttenaere K, Posada-Villa J, Gasquet I, Kovess V, Lepine JP, et al. (2004) Prevalence, severity, and unmet need for treatment of mental disorders in the World Health Organization World Mental Health Surveys. JAMA 291: 2581-2590.

11. Abu-Helalah M, Al-Hanaqta M, Alshraideh H, Abdulbaqi N, Hijazeen J (2014) Quality of life and psychological well-being of breast cancer survivors in jordan. Asian Pac J Cancer Prev 15: 5927-5936.

12. Akel R, Darsa HE, Anouti B, Mukherji D, Temraz S, et al. (2017) Anxiety, depression and quality of life in breast cancer patients in the levant. Asian Pac J Cancer Prev 18: 2809-2816.

13. Fischer DJ, Villines D, Kim YO, Epstein JB, Wilkie DJ (2010) Anxiety, depression, and pain: Differences by primary cancer. Support Care Cancer 18: $801-810$.

14. Lin CC, Lai YL, Ward SE (2003) Effect of cancer pain on performance status, mood states, and level of hope among Taiwanese cancer patients. J Pain Symptom Manag 25: 29-37. 